\section{SOME AFFECTIONS OF EPIPHYSES.*}

\section{BY}

H. A. T. FAIRBANK, D.S.O., M.S., F.R.C.S., SENIOR ORTHOPAEDIC SURGEON, IEING'S COILEGE HOSPITAL; SURGEON TO THE HOSPITAL FOR SICK CHILDREN, GREAT ORMIOND STREET.

I PRopose to begin my address on some affections of epiphyses with an account of three traumatic cases, all boys of 16 years of age, and all sent up from the same school by the same doctor, Dr. A. M. Amsler. These cases seem to me of importance, since the lesion in each case is easily missed unless perfect radiograms are available. They emphasize the importance of $x$-ray examinations in all cases, however trivial, in which it is possible that a lesion of a bone has occurred.

The first is an early separation of the femoral head-that is, an early adolescent coxa vara. A common history in such a case is that of a series of two or three minor accidents, such as falls in the football field, leading in each case to a limp, which finally becomes persistent and increases. It is of the greatest importance to recognize this condition in its early stages and to take steps to prevent its increase, but it is rare, in my experience, for the surgeon to see a case before considerable displacement has occurred.

A boy, aged 16, in Septembase I.

in hurting himself much, and on return to school he fell Iwice in the football field and hurt his right hip; after the second fall the hip continued to give pain; the pain was in the groin and on the oute side of the hip; a trip increased the pain whon seen, a month or so later, he was limping and the pain was increased by walking or even moving the hip when sitting.

On examination the hip showed no deformity, hat there was slight fullness in the groin with tenderness here and over the trochanter. Abduction and internal rotation were limited; flexion and extension were only slightly limited. Shortening amounted to three-eighths of an inch, and there was slight wasting. There was pain on jarring the heel, and also, though less marked, on jarring the trochanter. The skiagram shows widening of the epiphysea line and definite though slight depression of the rirht fomseal jead on the neck. Weight extension was applied and the leg put up in abduction and internal rotation, these two being increased lay in abduction and internal rotation, these two being increased lay by day till extreme limits were reached, when the limb was
ixed in plaster-of-Paris. It was hoped that the small amount of displacement of the head of the femur might be corrected, but unfortunately this was not achieved. 'The plaster cast was left on for three months and a walking calliper worn for a year. No increase of the deformity occurred.

$$
\text { CASE 1T. }
$$

The next case, also a boy aged 16, after falling once or twice in the football field without hurting himself particularly, noticed pain in the left hip while running, and found he could not kick with the left foot. After this game he played twice only, as on each the lection he had experienced pain played twice only, as on In an hour or so the pain had disappeared, and he only felt the hip on twisting or jumping. Walking caused no pain and there was no limp.

Physical examination was negative when seen three weeks after the onset, but some thickening of the trochanter had been noticed, and this had gone down with massage. A radiogram showed partial separation of the great trochanter, the space at the site of the epiphyseal line of the great trochanter being definitely wider on the left than on the right. Abstinence from all games for a couple of months or so effected a cure.

Separation of this epiphysis is usually complete and the result of direct violence. Although it might be expected that muscular action would be a not uncommon cause, the lesion usually results from direct trauma. A few cases due to muscular contraction have been recorded, but they are not very convincing. The commonest period for its occurrence is from the thirteenth to the sixteenth years. The displacement is usually not great and the diagnosis is difficult. In the recorded cases, mostly reported some year's ago, a surprising number seem to have been complicated by infection of the haematoma. Of 11 cases (Poland) 6 were followed by suppuration and 5 of these died. Some seem to have been primarily infective osteomyelitis with secondary separation of the epiphysis.

CASE III.

This patient showed an even rarer injury. A lad of nearly 17 complained that while playing football .and running all out the left hip suddenly hurt him and gave way so that he fell out the left hip suddenly hurt him and gave way so that he fell, another
boy falling over him. He finisher the game, but with pain. When boy falling over him. He finished the game, but with pain. When but any attempt at running caused considerable pain. He did not * Presidential Address to the Section of Orthopaedics of the Royal
Society of Mcdicine, October 7th, 1924. limp and no physical signs were present. The radiogram shows separation of the epiphysis of the anterior inferior iliac spine, the centre for wlich appears at the fifteenth year or later. Games were forbidden for a few wecks.

This would seem to be a very rare injury. Poland gives a few cases in his wonderful treatise on epiphyses. This injury usually gives rise to greater disability than in my case, the hip being flexed, and it is difficult or impossible for the patient to extend the hip and the knee. Soft crepitus may be obtained. The arulsion usually occurs in sprinters in the violent effort of starting a race. The reflected head of the rectus, which is not torn, prevents great displacement.

We may now pass on to consider the tubercle of the tibia. While there is some doubt as to whether the so-called Schlatter's disease is necessarily traumatic in origin, though certainly aggravated and kept up by the pull of the ligamentum patellae, there is no doubt that all types of cases are met with, from the complete traumatic avulsion of the tubercle to the case where no displacement is present and trauma seems to play no part in the onset.

The following case ${ }^{-}$is at one end of the series, and is, I think, exceptional in that the plane of fracture passed up through the epiphysis into the joint, the anterior part of the articular surface of the tibia being displaced. A boy of 14, while attempting to jump a lope, felt something give in the knee as he took off with the left foot. A skiagram showed the displaced fragment to consist of the anterior third of the articular surface of the tibia as well as the tubercle. At operation the fragment was forced back into place and fixed there with a beef-bone screw, the drill hole being tapped to fit the screw. The result was entirely satisfactory. In another case, that of a boy aged 14 who had had srmptoms for four months, a radiogram of the knee showed the typical fluffy condition of the tongue-like process forming the tubercle and of the bone beneath it, with some irregularity of the intervening cartilage. Abstention from all games for a time has been sufficient in most of my cases to relieve symptoms, though the possibility of a recurrence cannot be said to have disappeared till fusion of the tubercle with the shaft of the bone has occurred.

I now want to refer to a less known, though not less common, affection of a similar nature-namely, osteochondritis of the heel epiphysis. This, like the affection preceding it, and that which is to follow, is an affection of an epiphysis to which a strong tendon is attached, so that trauma would naturally be expected to play a part in the causation. While in "Schlatter's knee" trauma plays a more prominent part than in the others, it is difficult to get away from the impression that a mild infection must play a part in all, and more particularly in the cases of the heel and of the navicular tubercle to be mentioned later. This infection and resulting inflammatory change is necessarily aggravated by the pull of the tendon attached to the affected epiphysis, and there is no doubt that violent exercise does increase the symptoms and that rest is followed by partial or complete relief. While in the case of tho tibial tuhercle, as already mentioned, definite traumatic displacement, partial or complete, does occur as a result of violent action of the quadriceps, I know of no convincing case of separation of the epiphysis of the os calcis, nor of the navicular tubercle, though $I$ have one case to show you of fracture of the os tibiale externum. The vast majority, if not all the cases of supposed tearing off of the navicular tubercle, are really explained by the presence of a separate centre of ossification in this tubercle-the so-called os tibialo externum. Although in the affection under consideration an infective focus is probably present, it is not easy to find as a rulc. More than one writer has drawn attention to the similarity of these affections to pseudo-coxalgia and to Köhler's disease. In the case of the former, the femoral head being an epiphysis subject to very considerable strain, the similarity is striking, but in Köhler's disease the radiographic similarity between the affections is not nearly so convincing, nor in this case is the bone, the tarsal scaphoid as a whole, subject to an unusual amount of strain.

Osteo-chondritis of the heel affects bors rather more frequently than girls and is more commonly bilateral than 
milateral, the left heel being affected in my small series of fourtien cases much more frequently than the right. The ages of the patients varied from $8 \frac{1}{2}$ to 15 years. In only one, in whom the affection was started by a jumping competition, was anything in the way of unusual trauma discorered. The diagnosis depends on local pain and tenderness and the $x$-ray changes. The pain is definitely in the heel and not beneath it, and is aggravated by violent exerrise; the tenderness is on one or both sides, at the margin of the epiphyseal line, and occasionally at the back of the heel; swelling may be present, but is often absent. Flatfoot may be present, and occasionally there is some shortening of the calf muscles. Radiograms show a fluffy, eatenout, or fragmented epiphysis with unusual irregularity of the adjacent posterior surface of the body of the os ralcis. Great irregularity of this surface has been met with-in a large number of radiograms specially examined-only when srmptoms of the disease had been present at some time or other in the case. It must be remembered that the epiphrsis may ossify by more than one centre, and, as in the case of Schlatter's disease, radiograms must be examined in conjunction with the clinical evidence, unless the changes are very marked or unilateral. This is apt to be a chronic complaint, and while only occasionally is complete rest, even in plaster, indicated, abstention from all violent exercise mav have to be enforced for several months. Cure, as in the case of the tibial tubercle, takes place when fusion of the epiphysis with the rest of the bone occurs, but fortunately symptoms may subside long before this. The later the affection occurs the better, therefore, the prognosis. One case of a relapse after an interval of two rears was met with. I will now show you radiograms of three cases:

(ii) A girl, aged $8 \frac{1}{2}$, with pain on the inner side of the left heel of some months' duration.

(b) A boy, aged 12, with pain in the right heel for two months. Irregularity of the subepiphyseal eurface of the body of the bone is well marked. Later the other heel developed symptoms.

(c) A girl, aged 13, with pain in the right leeel of two months' duration. She complains of pain and tenderness after running or jumping. Flat-foot is present. The radiogram shows fragmented, fluffy epiphysis on the right side.

Precisely similar in nature is an affection of the tubercle of the taisal scaphoid, to which is attached, of course, the tibialis posticus tendon. I have seen both the scaphoid and the os calcis affected in the same foot. It may be as well to say that I am not speaking of Köhler's disease, or isolated disease of the navicular, but of an entirely different condition. Here we are dealing with an affection of the naricular tubercle only, and not of the whole bone. A child or adolescent complains of painful flat-foot, the naricular tubercle being unusually prominent, painful, and tender, the tenderness being usually on the posterior aspect of the process rather than on the tip, which might well le rubbed by the boots. An interesting fact, and one I have not seen mentioned, is that almost invariably a separate centre of ossification is present in these cases for this tubercle-the so-called os tibiale externum. In 11 cases, with bilateral symptoms in 7, making 18 feet in all, one or more centres of ossification for the tubercle were present in 13, in 2 others there is a questionably minute fragment of bone, while in one double case radiograms are not arailable to decide the point. The presence of an epiphysis at this point makes the anatomical conditions similar to those in the heel and the tibial tubercle. In only one or two has there been any suggestion of fluffiness of this epiphysis, if we may so call it. Girls are nearly twice as commonly affected as boys, in contrast to the heel cases, the ages varying from $9 \frac{1}{2}$ to 16 years in $m y$ series, the girls being rather younger. The sides are equally affected. The undue prominence of the tubercle, which is of course extremely common in painless flat-feet in children, is often equally great on the two sides, even though signs and symptoms are unilateral, while the os tibiale externum is usually bilateral. It is not known, so far as $I$ am aware, what is the usual fate of this bone. It certainly may remain as a separate fragment throughout life, "while the appearances seen in some feet strongly suggest that a separate bone had been present and had united to the navicular. The feet are almost invariably flat, and in rare cases the calf is contracted. These cases are not quite so obstinate as the heel cases. Treatment should aim at supporting the arches and ordering a varying degree of rest according to the sererity of the symptoms. Plaster may be advisable for a time. Exercises, etc., for the cure of the flat-foot must be delayed till all pain and tenderness have disappeared. I will show you radiograms of three typical examples:

(a) Boy, aged 13, with local pain and swelling for ten days only of the left navicular tubercle. Slight valgus was present; os tibiale externum on both sides, but larger on the left.

(b) Girl, aged 14, with bilateral flat-foot. Prominent navicular tubercle on the left. Tender at back. Pain on walking much for some weeks. There is some irregularity of the os tibiale externum on the left.

(c) Boy, aged 13, with prominence of both navicular tubercles, but only the right was tender at back. Three fragments of bone but only the right was tender at back. Three
are seen in the region of the navicular tubercle.

Another radiogram is from a woman of 51 who had turned her ankle in 1923 and had had pain in the foot ever since. An os tibiale externum is present on both sides, but on the right the bone is apparently fractured. I have not met with a similar radiogram. A month's rest was followed by return of pain as soon as she got up again. Removal of the bone was recommended.

I now want to show you a radiogram in which is seen a separate centre of ossification for the internal malleolus. This is a very rare condition and apparently unknown to many anatomists. Curiously enough I have met with 5 cases: in 3 the condition was bilateral, in 2 unilateral; 4 had serere flat-foot with pain, one also having peroneal spasm: the condition was only revealed by routine $x$-ray examination. Only 2 showed any local signs, and in these the tenderness, and in one also some swelling behind and below the malleolus, rather suggested teno-synovitis of the tibialis posticus tendon, but this could not be connected, directly at any rate, with the presence of this separate epiphysis. The radiogram shown is from a girl aged 10 who complained of pain and flat-foot. She had been kicked on the right ankle five months previously, and when seen there was a puffy, tender swelling below the internal malleolus on this side. The separate epiphysis is bilateral. It is extremely unlikely that the existence of this epiphysis had any relation to the symptoms.

Lastly I show you a case of dislocation of the elbow with separation of the epiphysis of the internal epicondyle. During reduction by the doctor, the separated internal epicondyle was by some chance caught between the humerus and ulna. At operation we were able to free the detached piece of bone, and, after drilling it, to stitch it back somewhere near its correct position. This would appear to be a very rare condition, though, as often happens with rare affections, four such cases have been met with in the last two rears; in each the diagnosis has been confirmed at operation. It would appear to be advisable to keep these cases in mind, particularly when recovery is delayed after reduction of a dislocation of the elbow.

\section{A DIABEIIC DIET: THE LINE RATION SCHEME.}

\section{R. D. LAWRENCE, M.A., M.D.ABERD.} CHEMICAL PATHOLOGIST, KING'S COLLEGE HOSPITAL.

Everyose recognizes that the most difficult part of the battle, both for the doctor and the patient, is not the insulin but the quantitative diet necessary in severe cases. A diet should be accurate and simple and yet permit of variety to suit all tastes and purses. If the diet is accurate and simple yet rigid, like Dr. Graham's "ladder" diet, it often defeats its own object by the patient getting tired of the monotony. If the scheme is accurate and still permits of choice and variety, like the scheme of Dr. Harrison and myself, ${ }^{1}$ where the prescription of so many grams of carbohrdrate, protein, and fat has to be translated into weights of food by the patient himself or his doctor, a few dars' training and explanation is required, unless the patient is intelligent. 